\title{
DETERMINANTS OF FERTILITY STATUS AMONG REPRODUCTIVE AGE WOMEN IN RURAL ETHIOPIA: EVIDENCE FROM 2016 ETHIOPIAN DEMOGRAPHIC HEALTH SURVEY
}

\author{
Mengistu Abebe Tegegne ${ }^{1}$, Alemneh Amesalu Fekadu², Gezahegn Mengesha Negassa ${ }^{3}$ \\ Department of Statistics, College of Natural and Computational Sciences, Dire Dawa University, Ethiopia; P.O.Box: \\ 1362 \\ Email: $\underline{\text { menge23a@gmail.com }}{ }^{1}$
}

\begin{abstract}
Background: Fertility rate is a significant determinant of population growth worldwide. Global population is growing about 80 million people each year. Ethiopia is one of the most heavily populated countries in the world. Objective: The objective of this study was to assess the major determinants of fertility status among reproductive age women in rural Ethiopia. Methods: The study used 2016 Ethiopian Demographic and Health Surveys data. A total of 8464 rural women aged 15 to 49 years included in the analysis. Poison Regression model was used to determine factors moving fertility status of rural women. Results: The overall average children ever born to women in rural regions were 5.1 children per women. Poisson regression analysis revealed that region, age group of respondents, education level, religion, household wealth index, sex of the head of the household, contraceptive use, age at first birth and mass media were found to be statistically significant factors for fertility rate of women. Conclusion: To reduce the gap of fertility rate between regional women, it is important to renovate different factors. These factors could be access to education, informing about contraceptive use, informing about family planning, enhancing to mass media. Therefore, the government and concerned bodies should plan effective strategies to increase the experience of using contraceptive across the country with transport limited regions. In addition to this, it is important to develop and keep the access of family planning services and the government could also uphold an access of education system for those restricted regions.
\end{abstract}

Keywords: Fertility, Women, EDHS, Poisson Regression

DOI: $10.7176 / \mathrm{MTM} / 9-10-01$

Publication date: October $31^{\text {st }} 2019$

\section{Background}

World population is growing about 80 million people each year. Almost all of the major problems that pressure the world are linked with rapid population growth. Fertility rate is an important determinant of population size. It stimulates health risk, poverty, water scarcity, environmental depletion and political instability [1]. Reduction of 
total fertility rates (TFR) is a key determinant of overall reduction in population growth and transition from high to low fertility. These in turn may have important consequences for economic growth, poverty reduction, and improved health and nutrition outcomes [2,3]. Demographically observed fertility or infertility is the result of a well-defined number of both biological and behavioral factors, which serve to mediate the influence of culture, society, economic conditions, living standards, and other similar background determinants on individual reproductive behavior.

In sub-Saharan Africa, the prevalence of contraceptive practice is low, and fertility levels are exceptionally high. In most resource poor countries, particularly sub-Saharan Africa, modern contraceptive use and prevalence are unusually low and fertility is very high resulting in rapid population growth and high maternal mortality and morbidity [3, 4]. In developing countries and sub-Saharan countries, fertility rate is high as compared to the rest of the world, mainly due to poor education; women have no careers, low contraception.

Similarly, in Ethiopia, there is high fertility and rapid population growth rate. Ethiopia is one of the most populous countries in the world [5,6] with an estimated total fertility rate of 5.4, 4.8, and 4.6 children per woman in 2005, 2011 and 0216 [7, 8, and 9]. It is observed that there is a clear difference in fertility rates in the country regarding to residence and regions. Because agriculture is the major economic sector in Ethiopia, most families want to have large number of children. For most of rural areas, the children assist their parents in farming activities, i.e., the economic importance of children are over lifetime. Similar to many countries in sub Saharan Africa, having many children is considered as an advantage and gift of God in a number of Ethiopian rural communities [10].

\section{Statement of the problem}

Population growth and high fertility rates in resource poor situations are a challenged problem for both the society and individuals in developing countries. Resource poor countries with population growth are challenged to create jobs for potential workers while their governments lack resources to meet increasing demand for services and infrastructure [26]. The effect of high fertility is also challenging for individuals. When several children are born to one mother, there is an economic burden on her household and an increased chance of the household entering into shortage of food and poverty [27]. Ethiopia is the $12^{\text {th }}$ most crowded country in the world [25] with estimated total fertility rate of 4.6 children per woman [9]. Although, Ethiopia has little declines in fertility rate from 4.8 children per women in 2011 to 4.6 children per woman in 2016, the change are varied among different organizational regions of the country. Total fertility rate is lowest in Addis Ababa (1.8 children per woman) and highest in Somali (7.2 children per woman) in 2016. Moreover rural-urban residence has a gap in total fertility rate in 2016. Women in rural areas have an average of 5.2 children, higher fertility compared to 2.3 children among women in urban areas [9]. Thus, this study was focused in rural areas of Ethiopia, where fertility rate is higher as compared to urban areas of the country. 


\section{Objective of the Study}

The main objective of this study was to assess the determinants of fertility status among reproductive age women in rural Ethiopia evidence from EDHS2016.

\section{Literature Review}

Studies done in different countries identified various differentials of fertility. Different researchers have been identified numerous factors that are determinants of fertility among reproductive age women. Like contraceptive use, levels of education, religion, and household wealth index, sex of the head of the household, age at first birth, Gender preference, employment status, family size and mass media are the key factors in explaining the discrepancy of fertility.

A study employed in Sudan using Poisson Regression model showed a significant relationship between fertility rate and high level of education, wealth index and contraceptive use. The richest quintile was statistically significant at $5 \%$ level of significance, indicating that fertility rate was higher among poor people compared to the rich. Educated women had fewer children than uneducated women. The findings also suggested that women who did not use contraceptive method had more children than women who experienced contraceptive method [11]. A study conducted in Uganda also indicated that a woman's contraceptive behavior; marriage status, wealth status and region of residence are important predictors of fertility outcomes. The results also showed that higher education levels and urban residence are consistently associated with lower fertility rates and are positively associated with contraceptive use [19].

According to study done in Butajira, indicated that age at first birth, education, food shortage, family size and sex preference are an important factors of fertility rate. Educational status of women had also been consistently and significantly found to be negatively associated with fertility. Women who had never been into any formal education had 1.24 times more children compared to those who completed secondary and above level of education. Similarly women who had no sex preference to their children had about 9 percent higher fertility compared to those with sex preference [13]. The results of study done in Rwanda showed lower fertility among women with more education and with greater household wealth. The IRR was 0.960 .900 .66 respectively for women with primary, secondary and higher education levels compared to women with no education. Similarly, low fertility was associated with Household wealth (highest versus lowest quintile: IRR $=0.58$, and having contraception use; IRR $=0.69$. [24].

The multiple Poisson regression of CEB conducted in Nigeria showed women with secondary and higher education were about $5 \%$ and $23 \%$ times (IRR $=0.77,95 \% \mathrm{CI}: 0.75-0.80)$ less likely to have children as women with no formal education. The employed women were 1.03 times more likely to have children than unemployed women. Respondents in richest wealth quintile were 0.92 times less likely to have as many children as the poorest respondents [19]. 


\section{Data and Methodology}

\section{Data Source}

Data obtained from the Ethiopian Demographic and Health Surveys (EDHS) conducted in 2016 were used. Surveys were conducted by Central Statistical Agency (CSA) of Ethiopia. The surveys were nationally representative cross sectional study that collected comparable demographic and health data on women aged 15-49 during the survey periods. The women were asked about their birth histories and this provided information about the total number of children ever born [9]. This study was based on secondary analysis of data among women aged 15-49 years collected in the 2016 demographic and health surveys. A total of 8464 rural women included in the analysis.

\section{The Model}

The outcome variable, fertility status is defined as the total number of children ever born (CEB) to women in the childbearing age (15-49 years). It is a count variable that takes a nonnegative integer value. Poisson regression Incidence Rate Ratio with 95 percent confidence interval (CI) is appropriate to assess the association of various predictors with dependent variable fertility [25]. Poisson regression deals with situations in which the dependent variable is a count and the expected value is similar to the variance for each observation. Since, total children ever born to women in the reproductive age group which is a count data is measured as the outcome variable for this study, the researcher adopted a generalized linear model with a natural log- link function (Poisson regression). The expected value of the count variable $(y)$ conditional on a set of predictor variables $\mathrm{x}$ is given by.

$$
\mathrm{E}(y / x)=\mathrm{e}^{(\mathrm{x} \beta)}=\Lambda
$$

This condition assures that $\mathrm{E}(y / x)>0$

Then the probability of children born is given as:

$\mathrm{P}(Y=y / x)=\frac{e^{-\mathrm{x} \beta} \mathrm{x} \beta^{\mathrm{y}}}{y !}$, Where $\mathrm{y}=0,1,2, \ldots, \mathrm{n}$

The maximum likelihood Poisson fertility equation is then specified as:

$L(\beta)=\sum_{i=1}^{n}\left\{y_{i} x_{i} \beta-e^{x \beta_{i}}\right\}$

The full model is therefore given as:

$\Lambda=e^{\beta_{0}+} \sum_{j=1}^{k} \beta_{j} x_{j}$

$\Lambda=$ The expected number of children per woman $\mathrm{i}$

$\mathrm{e}=$ The base of natural logarithms; 
$\beta_{0}=$ The intercept

$\beta_{j}^{\prime} s=$ Regression coefficients

$x_{i} s=$ The independent variables

The conditional mean and variance of the dependent variable are constrained to be equal for each observation. Poisson regression is a nonlinear regression analysis of the Poisson distribution, where the analysis is highly suitable for analyzing discrete data (count) if the mean equal to the variance process. Poisson distribution is a limiting case of the binomial distribution when the number of trials becomes large while the expectation remains stable, i.e., the probability of success is very small.

\section{Results and Discussion}

Data analysis was done using SPSS version 20 for windows. The data was cleaned and preliminary analysis was done by the investigator. The overall significance of each covariate was first checked and those variables statistically significant in the bi-variate analysis were also included in multivariate Poisson regression model to compute Incidence Rate Ratio (IRR). Independent variables were; Region (regional state of respondents), Age (current age group of respondents), Education (highest education level attained by the respondents), family size of the household, religion (religion of respondents), household wealth index, sex of household head (sex of the head of the household), contraceptive use (current use of any contraceptive method), age at first birth (age at first start of delivery), employment status, gender preference and mass media.

\section{Results of Descriptive Statistics}

As we have seen from Table 1, the overall average children ever born to women in the reproductive age group was found to be 5.1 children per women (standard deviation $=2.6$ ).

Table1. Summary for children ever born to women

\begin{tabular}{|l|c|c|c|c|}
\hline Fertility status & N & Maximum & Mean & Sat. deviation \\
\hline Total children ever born & 8464 & 14 & 5.1 & 2.6 \\
\hline Total & 8464 & & & \\
\hline
\end{tabular}

\section{Interpretation for Multivariable Analysis results}

The results of the multivariable analysis are presented in Table 1\&2. Analysis of Poisson regression showed the major significant factors of fertility status among rural women were identified. We can interpret the Incidence Relative Ratio of each factor depending on 95 percent confidence interval and P- value. If the confidence interval not includes 1 and the P-value is less than 0.05, then the variable is significant and can be interpreted as the average 
number of children born to women at the given category differs from the average number of children born from the reference category. As the result indicates, the highest fertility is found in Somali region in the country. The average number of children ever born for women in Somali region was 1.131 times more likely than that of children ever born for women in the reference category (Dire Dawa). The average fertility rate for women in Gambela region was $10.1 \%(\mathrm{IRR}=0.899,95 \% \mathrm{CI}, 0.854-0.945)$, in Amhara region was 9.7\% (IRR $=0.903,95 \% \mathrm{CI}, 0.858-0.951)$ and in Harari region was $5.7 \%$ (IRR $=.0 .943,95 \%$ CI, 0.891-0.99) lower compared to Dire Dawa. Regarding to household head, the average number of children born for women in male headed group was $6.7 \%$ higher than the expected number of children born for women in counterpart (IRR $=1.067,95 \% \mathrm{CI}, 1.047-1.089)$. A significant association between fertility rate and religion is showed that Muslim mothers had $4.3 \%$ higher mean fertility compared to women with protestant beliefs (IRR $=1.043,95 \% \mathrm{CI}, 1.015-1.0871)$. On the other hand, mothers who were orthodox beliefs had $3.9 \%$ lower average children ever born compared to protestant $($ IRR $=0.961,95 \%$ CI, 0.932 0.990).

From the result, it was found that Educational status of women had also been consistently and significantly found to be negatively associated with fertility. Women who have no education have $24.4 \%$ higher average children ever born as compared to women who have attended secondary and higher education (IRR $=1.244,95 \%$ CI, 1.1781.315). Similarly, women who have attended primary education have $10.7 \%$ higher average children born than counterpart $(\mathrm{IRR}=1.107,95 \% \mathrm{CI}, 1.048-1.170)$. likewise, women whose husband have no education have $5 \%$ higher average children born compared to women whose husband have secondary and higher education (IRR $=$ $1.050,95 \%$ CI, 1.018-1.083). The same, women whose husband have attended primary education have $4.7 \%$ higher average children born than counterpart (IRR $=1.047,95 \% \mathrm{CI}, 1.014-1.080)$. The other predictor variable of fertility rate is economic status of the household. Women in the poorly economic group had $2.7 \%$ higher average number of children than the expected number of children of women in the richly economic group (IRR $=1.027,95 \% \mathrm{CI}, 1.006-$ 1.049). This indicates that women who have better facility leads to have the lower fertility rate. Contraceptive is also the most important factor of fertility of women. As the findings showed, women who did not use contraceptive had 9.2\% greater average fertility compared to women who used contraceptive (IRR $=1.092,95 \% \mathrm{CI}, 1.070-1.113$ ). The average number of children born for women who started their first birth before the age of 19 years old was 1.402 times than women who delivered their first birth in greater or equal to19 years old $(\mathrm{RR}=1.402,95 \% \mathrm{CI}, 1.380$ 1.425). On the other hand, the average fertility of mothers whose age group is less than 25 was $68.5 \%$ lower than that of mothers whose age group is between 35 and 49. In the same way, mothers whose age group is between 25 and 34 had $36.9 \%$ lower average children born compared to the reference category. Mass media about family planning is also an important factor for fertility status. The average number of children born for women who got information from mass media was 0.961 times less likely than women who did not get mass media $($ IRR $=0.961$, 95\% CI, 0.932-0.990). 
Table2. Poisson Regression Analysis to Estimate Parameters of Determinants for Fertility Status among Women in Rural Ethiopia, 2016 EDHS

\begin{tabular}{|c|c|c|c|c|c|}
\hline Predictors & Estimate & P-value & IRR & $95 \%$ LCI & $95 \%$ UCI \\
\hline Tigry & -.049 & .073 & .953 & .903 & 1.004 \\
\hline Affar & .001 & .975 & 1.001 & .956 & 1.047 \\
\hline Amhara & -.102 & .000 & .903 & .858 & .951 \\
\hline Oromiya & .035 & .117 & 1.036 & .991 & 1.083 \\
\hline Somali & .123 & .000 & 1.131 & 1.083 & 1.182 \\
\hline B-Gumuz & .019 & .437 & 1.019 & .972 & 1.068 \\
\hline SNNP & .008 & .752 & 1.008 & .960 & 1.058 \\
\hline Harari & -.058 & .045 & .943 & .891 & .999 \\
\hline Gambela & -.106 & .000 & .899 & .854 & .945 \\
\hline Region (Dire Dawa. ref) & & & 1 & & \\
\hline Male & .065 & .000 & 1.067 & 1.047 & 1.089 \\
\hline Orthodox & -.040 & .010 & .961 & .932 & .990 \\
\hline Muslim & .042 & .002 & 1.043 & 1.015 & 1.071 \\
\hline Religion (Protestant or other) & & & 1 & & \\
\hline No education & .049 & .002 & 1.050 & 1.018 & 1.083 \\
\hline Primary & .046 & .004 & 1.047 & 1.014 & 1.080 \\
\hline Husbands educate (Second+. ref) & & & 1 & & \\
\hline No education & .219 & .000 & 1.244 & 1.178 & 1.315 \\
\hline Primary & .102 & .000 & 1.107 & 1.048 & 1.170 \\
\hline Women educate (Second+. ref) & & & 1 & & \\
\hline Not used & .088 & .000 & 1.092 & 1.070 & 1.113 \\
\hline Contraceptive(Used. ref) & & & 1 & & \\
\hline Economic Level (Rich.ref) & & & 1 & & \\
\hline$<19$ & .338 & .000 & 1.402 & 1.380 & 1.425 \\
\hline Age of women at first birth $(\geq 19$.ref $)$ & & & 1 & & \\
\hline$<25$ & -1.166 & .000 & .312 & .305 & .319 \\
\hline $25-34$ & -.461 & .000 & .631 & .621 & .641 \\
\hline Age group (35-49.ref) & & & 1 & & \\
\hline Yes & -.048 & .074 & .960 & .904 & 1.005 \\
\hline Currently working (No.ref) & & & 1 & & \\
\hline Yes & -.040 & .010 & .961 & .932 & .990 \\
\hline Mass Media (No.ref) & & & 1 & & \\
\hline $\operatorname{Large}(>=4)$ & .036 & .113 & 1.037 & .992 & 1.084 \\
\hline Household Size (Small<4.ref) & & & 1 & & \\
\hline Yes & .014 & .568 & 1.014 & .963 & 1.069 \\
\hline Gender Preference (No.ref) & & & 1 & & \\
\hline
\end{tabular}




\section{Discussion}

In this study, the overall fertility rates 5.1 children per woman was almost similar to the findings of other studies done in Sudan, Gondar, North West Ethiopia, Butajira, Ethiopia [11,12 and 13]. The fertility level is still high in the country. This could be attributed to the acceptance of the wider community to large family size mean as children assisted households in survival farming. Though disparities were observed across major regions of the world, children were considered as assets to their parents when they get older. On the other hand, mothers who had never been enrolled into any formal education system and who attended primary education had significantly higher children as compared to those who had secondary and plus education. This confirms with the other studies [14, 15, 23 and 24] and may be attributable to the rearrangement of childbirth due to longer schooling. A study conducted in Sidamas, Southern Ethiopia indicated that fertility was higher among women with primary level of education compared to those who never attended any formal education. Fertility levels are lower among highly educated women. Higher educational level of women gives an opportunity of social and economic empowerments. Thus, talented women might feel that they could take care of many children and decided on for large family size. This is consistent with the claim by some researchers that increased family income leads to increased fertility when family planning use is low $[13,16]$.

Although, contraceptive use among women in Ethiopia was still low, our findings indicated that contraceptive use contributed significantly to the change in number of children ever born. This finding points to the need for continued and increased government and international support for quality family planning if sustainable fertility reduction is to be achieved. This finding confirms what numerous studies have declared about contraceptive use significantly driving fertility change [17-19]. Women who practiced contraceptive method had lower children than women who did not practice contraceptive use. This is in agreement with the findings from Ghana and Namibia indicated that a woman's contraceptive behavior as important predictors of fertility outcomes [20-22].

In addition, women who married early in life and got the first birth early had an increased risk of having many children, in particular, if they started childbirth before the age of 20 years. On the other hand, several studies have shown that delay of first childbirth to later ages leads to fertility reductions since women would have fewer years of reproduction window which may introduce parity specific controls even after the initiation of child birth [13, 16]. Our study also suggested that women who gave their first birth below 19 ages were higher than that of counterparts. Religion also has an effect on the status of fertility. The finding of this study indicated Muslim women have more children as compared to the reference category, protestant women. Based on the economic status of the household, women who have worse facilities tend to have higher fertility. This implies that in areas where traditional social and economic systems prolong the level of fertility. This is in consistent with the other report studied in Nigeria by [23] that respondents in richest wealth quintile were less likely to have as many children as the poorest respondents. Hence, for essential change in fertility level, it is important to breakdown the traditional social system. In addition to this, it is important to have transformation of the economy. The finding of this study indicated, employed status was not a significant factor of the number of children that women would have. This is inconsistent with the findings reported by other study, where currently working of women was strongly associated with high fertility [23]. 


\section{Limitations of Study}

There were several limitations to this analysis. First, this study was based on secondary analysis of cross sectional study of data so the results represent relations only; we cannot draw conclusions about causality of low and high fertility status unlike prospective study. Second, we were not able to investigate associations of fertility with all potential factors of fertility because they were not incorporated in the survey.

\section{Conclusion and Recommendations}

The descriptive result showed the overall average children born to rural women in the reproductive age group is still high, 5.1 children per women (standard deviation $=2.6$ ). The variability of fertility rate was observed across regions of Ethiopia. The Poisson regression of multivariable analysis revealed that regional state of respondents, current age group of respondents, highest education level attained by the respondents, religion of respondents, household wealth index, sex of the head of the household, contraceptive use, age at first birth and mass media were statistically significant factors for fertility rate of Ethiopian rural women. While family sizes of the household, employment status and Gender preference were not significant variables for this study. To condense the gap of fertility rate between regional women, it is important to modernize different factors. These factors could be access to education, informed about contraceptive use, informed about family planning using mass media. Therefore, the government and concerned bodies should design effective strategies and act in a concentrated way to increase the experience of contraceptive use across the country with transportation limited regions. In addition, it is also important to develop and keep the access of family planning services and the government could also uphold an access of education system for those restricted regions.

\section{References}

1. Population Institute. Demographic Vulnerability: Where population Growthposes the greatest Challenges. America: Washington DC; 2015. Availablefrom: https://www.online

2. Tadesse F, Headey D. Urbanization and fertility rates in Ethiopia. Washington DC: International Food Policy Research Institute (IFPRI); 2012. pp. 1-25.

3. Rutaremwa et al. The contribution of contraception, marriage and postpartum insusceptibility to fertility levels in Uganda: an application of the aggregate fertility model, Fertility Research and Practice 2015 1:16

4. Erulkar A. Early marriage, marital relations and intimate partner violence in Ethiopia. Int Perspect Sex Reprod Health. 2013; 39:6-13.

5. United Nations, Department of Economic and Social Affairs, Population Division (2017). World Population Prospects: The 2017 Revision, DVD Edition

6. Al Awad. M. and Chartouni, C. Explaining the Decline in Fertility among Citizens of the G.C.C. Countries: the Case of the U.A.E. Institute for Social and Economic Research. 2014. Working Paper No. 1. 
7. CSA, ORC-Macro: Ethiopia Demographic and Health Survey 2005: Central Statistical Authority, Addis Ababa, Ethiopia; ORC Macro, Calverton, USA. 2006.

8. CSA, Central Statistics Agency of Ethiopia and ORCMacro: Ethiopia demographic and health survey 2011. Addis Ababa and Calverton, MD: Central Statistics agency and ORC Macro. 2012.

9. Central statistical agency (CSA) [Ethiopia] and ICF. Ethiopia demographic health survey. Addis Ababa, and Rockville: CSA and ICF; 2016

10. Bairagi, R., Effect of Sex Preference on Contraceptive Use, Abortion and Fertility in Matlab, Bangladesh. International Family Planning perspectives, 2001. 27(3): p. 137-143

11. Hesham Mohamed Hassen, etal: Using Count Regression Models to determinants of Factors Influencing fertility of Sudanese Women(2016).

12. Alene GD, Worku A: Estimation of the total fertility rates and proximate determinants of fertility in North and South Gondar zones, Northwest Ethiopia: An application of the Bongaarts' model. EthiopJHealth Dev 2009, 23(1):19-27

13. Mekonnen and Worku: Determinants of fertility in rural Ethiopia: the case of Butajira Demographic Surveillance System (DSS) BMC Public Health 2011, 11:782

14. Bhargava A: Desired family size, family planning and fertility in Ethiopia. J Biosoc Sci 2007, 39(3):367-81

15. Gebremedhin S, Betre M: Level and differentials of fertility in Awassa town, Southern Ethiopia. Afr J Reprod Health 2009, 13(1):93-112

16. Alene GD, Worku A: Differentials of fertility in North and South Gondar zones, northwest Ethiopia: a comparative cross-sectional study. BMC Public Health 2008, 8:397

17. Rutayisire, Pierre Claver, Pieter Hooimeijer, and Annelet Broekhuis. 2014. "Changes in fertility decline in Rwanda: a decomposition analysis.” International Journal of Population Research 2014:1-11.

18. Ezeh AC, Mberu BU, Emina JO. Stall in fertility decline in eastern African countries: regional analysis of patterns, determinants and implications. Phil Trans R Soc B. 2009;364:2991-3007

19. Ariho et al. Determinants of change in fertility pattern among women in Uganda during the period 2006-2011 Fertility Research and Practice (2018) 4:4 https://doi.org/10.1186/s40738-018-0049-1

20. Alamuleni ME. Determinants of fertility decline in Namibia: an analysis of the proximate determinants. Bangladesh e-J Sociol. 2017;14(2):41-63.

21. Mekonnen W, Worku A. Levels and proximate determinants of fertility in Butajira District, South Central Ethiopia. Ethiop J Health Dev. 2011;25(3).

22. Rutaremwa G, Galande J, Nviiri HL, Akiror E, Jhamba T. The contribution of contraception, marriage and postpartum insusceptibility to fertility levels inUganda: an application of the aggregate fertility model. Fertil Res Pract. 2015;1:16

23. Adeniyi F.Fagbamigbe*, and Ayo S. Adebowale. Current and Predicted Fertility using Poisson Regression Model: Evidence from 2008 Nigerian Demographic Health, Journal of Reproductive Health March 2014; 18(1): 71 
24. Ndahindwa et al. Determinants of fertility in Rwanda in the context of a fertility transition: a secondary analysis of the 2010 Demographic and Health Survey. Reproductive Health 2014, 11:87

25. United Nations, Department of Economic and Social Affairs, Population Division (2017). World Population Prospects: The 2017 Revision, DVD Edition.

26. Greene M: By choice, not by chance: family planning, human rights and development. Geneva: United Nations Population Fund; 2012.

27. Aassve A, Engelhardt H, Francavilla F, Kedir A, Kim J, Mealli F, Mencarini L, Pudney S, Prskawetz A: Poverty and fertility in less developed countries: a comparative analysis. Essex: Institute for Social and Economic Research; 2005 